\title{
Gestational trophoblastic disease findings of a five year period retrospective audit
}

\author{
Balvinder Sagoo $^{1 *}$, Nashwa Abulhassan ${ }^{2}$ \\ ${ }^{1}$ Department of Obstetrics and Gynaecology, Queen Charlottes and Chelsea Hospital, Du Cane Road, London, W12 \\ OHS \\ ${ }^{2}$ Department of Obstetrics and Gynaecology, Frimley Health NHS Foundation Trust, Slough, Berkshire SL2 4HL \\ Received: 18 September 2015 \\ Accepted: 31 November 2015

\section{*Correspondence:} \\ Dr. Balvinder Sagoo, \\ E-mail: bsagoo@doctors.org.uk \\ Copyright: (C) the author(s), publisher and licensee Medip Academy. This is an open-access article distributed under \\ the terms of the Creative Commons Attribution Non-Commercial License, which permits unrestricted non- \\ commercial use, distribution, and reproduction in any medium, provided the original work is properly cited.
}

\begin{abstract}
Background: To identify the incidence, characteristics and symptoms of women diagnosed with gestational trophoblastic disease (GTD) in an early pregnancy unit in Slough, Uk. To assess the accuracy of ultrasound diagnosis in detecting GTD in our early pregnancy unit at Wexham Park Hospital. To evaluate the management of patients diagnosed with GTD compared to RCOG guidelines.

Methods: Qualitative observational study, retrospective audit over a five year period. Frimley Health NHS Foundation Trust January 2010 - December 2014. Women diagnosed with GTD based on ultrasound or histological diagnosis. Patients diagnosed with GTD/ GTN were identified through registration with Charing Cross Hospital $(\mathrm{CXH})$, screening centre for GTD. Data was collected from CXH, WPH information databases: CRIS, PACs and ICE. Data was analysed and results presented.

Results: Over a 5 year period, 53 out of 21,995 pregnant patients were diagnosed with GTD (Incidence of 1 in 415) $62 \%$ of patients diagnosed with GTD were of white ethnic origin. Accuracy of ultrasound diagnosis in our unit was $40 \%$.

Conclusions: We found a high incidence of GTD in the non-Asian population (1 in 415). Most patients who had been diagnosed with GTD on ultrasound were in the first trimester. Accuracy of ultrasound diagnosis is $40 \%$ over a 5 year audit period. The main ultrasound findings of GTD were cystic changes and mixed echogenic echoes. Patients who were undiagnosed on ultrasound but had histological diagnosis of GTD had missed miscarriage as the predominant ultrasound diagnosis. Most patients were registered with the screening centre within six weeks of the histological diagnosis.
\end{abstract}

Keywords: Gestational trophoblastic disease, Ultrasound diagnosis, Characteristics, Symptoms

\section{INTRODUCTION}

The UK incidence of GTD is quoted as 1 in 714 live births, it has been noted to be higher amongst Asian females (1/387 live births) compared to non-Asian females (1/752 live births). ${ }^{1}$

GTD is rarely seen after a live birth $(1 / 50,000)$, but the risk of re-occurrence, especially with the same histological type is high $(1 / 80){ }^{2}$

Complete moles are most likely due to duplication of a single sperm following fertilisation of an empty ovum rather than di-spermic fertilisation.

Partial moles usually have evidence of fetal parts or fetal red blood cells and nearly all are triploid with two sets of paternal genes and one set of maternal haploid genes. ${ }^{3}$

GTD is a histological diagnosis, USS can help indicate the possibility of a molar pregnancy, and presentation can vary from irregular vaginal bleeding, hyperemesis, excessive uterine enlargement and failed early pregnancy. 
The Royal College of Obstetrics and Gynaecology green top guideline for Gestational Trophoblastic Disease suggest that all women should be provided with written information and referred for follow up by a trophoblastic screening centre.

\section{METHODS}

Retrospective data from women who were diagnosed with GTD at Wexham Park Hospital, over a period of five years from 2010-2014 was collected from $\mathrm{CXH}$ screening centre, WPH electronic databases: CRIS, PACs and ICE.

The accuracy of ultrasound diagnosis in detecting molar pregnancy and incidence, characteristics, symptoms of the local population was determined.

The management and registration of patients diagnosed with GTD was correlated according to RCOG guidance.

\section{RESULTS}

Fifty three patients were diagnosed with molar pregnancy over five years, $36 \%$ had a complete mole and $49 \%$ had a partial mole. Thirteen percent had persistent trophoblastic disease of which $3.7 \%$ were eventually diagnosed with non-persistent trophoblastic disease by $\mathrm{CXH}$. One of the patients had three previous molar pregnancies.

The incidence of molar pregnancy over the five year period was 1 in 415 .

The number of Asians diagnosed with GTD was $21 \%$ and Whites were $62 \%, 17 \%$ had ethnicity unspecified.

The patient age ranged from 16-55, majority were between the ages of $21-40$, up to $40 \%$ were between 21 30 years and up to $50 \%$ were aged between 31 and 40 years. Only $6 \%$ were over 41 years and under 16 years old.

Over half of the women diagnosed were primiparous and $30 \%$ multiparous, about half had been diagnosed with subfertility and one third had a history of previous miscarriage ranging from one to five.

Most patients diagnosed were between seven and twelve weeks pregnant, the remaining $10 \%$ were five weeks and 13 - 16 weeks of gestation or post early miscarriage.

More than half the diagnosis were from incidental finding, a third were diagnosed as a result of vaginal bleeding and less than $2 \%$ had persistently high BHCG.

Up to $50 \%$ had both (Trans-vaginal scan) TVS and (Trans-abdominal scan) TAS, up to $20 \%$ had a TVS only and $26 \%$ had a TAS only.
The use of ultrasound scan (USS) made the diagnosis of molar pregnancy likely in $40 \%$ of the patients; the suspicious features were missed miscarriage with cystic changes, irregular empty sac with snow storm appearance and an enlarged uterus with cystic changes in placenta or mixed echogenic areas and twin pregnancy with cystic changes.

Over half of the patients diagnosed with a molar pregnancy did not have any suspicious features on USS. Two thirds of the patients had a diagnosis of missed miscarriage; a few had a diagnosis of ectopic pregnancy, retained products of conception and a single viable intrauterine pregnancy.

The interval from USS findings to surgical management was within one week for majority of patients; less than $10 \%$ did not have the procedure till up to 4 weeks, $15 \%$ had the procedure within two weeks.

Only one fifth of suspected molar pregnancy was operated on by a consultant, the rest were evacuated by a registrar.

Most evacuations had no complications, less than $10 \%$ had an estimated blood loss (EBL) of 600 to $2000 \mathrm{ml}$.

All patients with a histological diagnosis of GTD were registered with $\mathrm{CXH}$; most were registered within 1-4 weeks and at 5-7 weeks, $13 \%$ were registered between 8 16 weeks and less than $2 \%$ were registered after 18 months of histological diagnosis.

There was a delay of 2 months between sample collection and histology arriving in the laboratory for $5.7 \%$ of patients.

\section{DISCUSSION}

\section{Main Findings}

Our hospital had a higher rate of GTD 1/415 compared to the UK figure of $1 / 714$, our incidence was higher in females of White ethnic background $60 \%$.

There have been numerous studies looking at the epidemiology and aetiology of GTD, majority state a higher incidence amongst the Asian population, the trophoblastic screening centre at Weston Park Hospital, Sheffield specifically studied the Asian population and determined the incidence of 1 in 387 live births, even the Netherlands found an increasing incidence of GTD most likely due to an increase in Asian women giving birth., ${ }^{5,6,7}$ There were no papers showing a higher incidence amongst the non-Asian population.

It has been shown that there is no relationship between treatment for infertility and development of GTD, ${ }^{8}$ so we cannot suggest our high sub - fertility rate, of which 
many patients may have had treatment for account for the high rate of GTD.

We had a 3 in 1000 incidence of complete mole and nearly 5 in 1000 incidence of partial mole. Incidence of complete mole has been reported as 1 in 1000 and for partial mole 3 in 10009 again our numbers are comparable with national statistics.

Persistent trophoblastic disease was approximately $10 \%$ which is representative of the national average showing that although the incidence is higher, the sequel is similar amongst our patient group.

Only $6 \%$ of women were over the age of 41 years old, this does not fit in with the risks of maternal age as rates are supposed to be 7.5 times higher for women over the age of 40 years. ${ }^{10}$

One third of women diagnosed with GTD had a history of miscarriage; As Parazzini et al $^{10}$ suggested this could be attributed to associated increase risk of molar pregnancy 2-3 fold if women had previous spontaneous miscarriage.

Majority of patients $(83 \%)$ were diagnosed within the 1 st trimester of pregnancy, but half of the patients were diagnosed as an incidental finding. This highlights the advancement of USS allowing GTD to be diagnosed before the onset of typical symptoms. ${ }^{11,12}$

USS detected $40 \%$ of molar pregnancy, as most of the diagnosis was before 14 weeks; this is representative of other studies that suggest a pre-evacuation diagnosis of molar pregnancy of $35-40 \%$ before 14 weeks. ${ }^{13}$

Majority of patients had ERPC within one week from USS suggesting possible molar pregnancy. There are no guidelines for when ERPC for possible GTD should be carried out as most GTD are diagnosed after evacuation from histology. Offering ERPC within one week is good practice as earlier treatment results in decrease of complications. ${ }^{14}$

Only $7.5 \%$ of patients had complications of bleeding more than $500 \mathrm{ml}$ during ERPC which again is a comparable incidence.

\section{Strengths and limitations}

This was a five-year study allowing us to collect a good amount of cases increasing the accuracy of the results.

One limitation of our study was that we could attribute our increased rate of GTD to a low socioeconomic class and diet but in order to discuss this further we would need to collect more data.

\section{CONCLUSIONS}

At Wexham Park Hospital we have a higher than national average GTD rate 1 / 415 verses 1 / 714 and in females of non-Asian ethnic origin mainly White women.

In order to provide safe, quality care for patients diagnosed with GTD and improve early registration with the screening centre, we had implemented tissue nonviability forms which are completed promptly with the specimens from surgical management of miscarriages and ectopic pregnancies. This allows specimens to reach the lab on time avoiding processing delays and subsequent histological diagnosis.

Early registration of patients diagnosed with GTD allows prompt appropriate management by the screening centre. It has become the unit's policy that EPU consultants should be responsible for early pregnancy patients and review histology reports from surgical management of miscarriages and ectopic pregnancies to ensure prompt registration of relevant patients with the screening centre.

As a high proportion of histological diagnosis were from patients who had been diagnosed with missed/ delayed miscarriage on USS it is essential that patients who are being offered expectant management or medical management have follow up USS 3 weeks after expulsion of products of conception and a urine pregnancy test to exclude molar or persistent trophoblastic tissue.

Funding: No funding sources

Conflict of interest: None declared

Ethical approval: The study was approved by the Institutional Ethics Committee

\section{REFERENCES}

1. Tham BWL, Everard JE, Tidy JA, Drew D, Hancock BW. Gestational trophoblastic disease in the Asian population of Northern England and North Wales. BJOG. 2003;110:555-9.

2. Sebire NJ, Fisher RA, Foskett M, Rees H, Seckl MJ, Newlands ES. Risk of recurrent hydatidiform mole and subsequent pregnancy outcome following complete or partial hydatidiform molar pregnancy. BJOG. 2003;110:22-6.

3. RCOG Green-top guideline, N0 38. 2010, Management of gestational trophoblastic disease.

4. RCOG Green-top guideline, 2011, Management of gestational trophoblastic disease.

5. Altieri A, Franceschi S, Ferlay J, Smith J. Epidemiology and aetiology of gestational trophoblastic diseases. The Lancet Oncology. 2003;4:670-8.

6. Tham BWL, Everard JE, Tidy JA, Drew D, Hancock BW. Gestational trophoblastic disease in the Asian population of Northern England and North Wales. BJOG. 2003;110:555-9. 
7. Lybol C, Thomas C, Bulten J, Dijck J, Sweep F, Massuger L. Increase in the incidence of gestational trophoblastic disease in the Neatherlands. Gynecology Oncology. 2011;121:334-8.

8. Bates M, Everad J, Wall L, Horsman JM, Hancock B.W. Is there a relationship between treatment for infertility and gestational trophoblastic disease? Human Reproduction. 2004;19:365-7.

9. Kenny L, Seckl M. Treatments for Gestational Trophoblastic Disease. Expert Review of Obstetrics \& Gynecology. 2010;5(2):215-25.

10. Parazzini F, LaVecchia C, and Pampallona S. Parental age and risk of complete and partial hydatidiform mole. $\mathrm{Br} \mathrm{J}$ Obstet Gynecol. 1986;93:582-5.

11. Mangili G, Garavaglia E, Cavoretto P, Gentile C, Scarfone G, Rabaiotti E. Clinical presentation of hydatidiform mole in northern Italy: has it changed in the last 20 years? Am J Obstet Gynecol. 2008;198(3):302.

12. Soto-Wright V, Bernstein M, Goldstein DP, Berkowitz RS. The changing clinical presentation of complete molar pregnancy. Obstet Gynecol. 1995;86(5):775-9.

13. Fowler DJ, Lindsay I, Seckl MJ, Sebire NJ. Routine pre-evacuation ultrasound diagnosis of hydatidiform mole: experience of more than 1000 cases from a regional referral center. Ultrasound Obstet Gynecol. 2006;27:56-60.

14. Al-Mulhim A. Hydatidiform Mole: a study of 90 cases. J Family community Med. 2000;7(3):57-61.

Cite this article as: Sagoo B, Abulhassan N.

Gestational trophoblastic disease findings of a five year period retrospective audit. Int J Reprod Contracept Obstet Gynecol 2015;4:1887-90. 